\title{
Blood Transfusion and the Risk of Cancer in the US Population: Is There an Association?
}

This article was published in the following Dove Press journal: Clinical Epidemiology

\author{
Amr Ehab El-Qushayri (iD) ${ }^{1, *}$ \\ Sherief Ghozy iD ${ }^{2 *}$ \\ Sara Morsy iD $^{3}$ \\ Faria $\mathrm{Ali}^{4}$ \\ Sheikh Mohammed Shariful Islam (iD) 5 \\ 'Faculty of Medicine, Minia University, \\ Minia, Egypt; ${ }^{2}$ Faculty of Medicine, \\ Mansoura University, Mansoura, Egypt; \\ ${ }^{3}$ Medical Biochemistry and Molecular \\ Biology Department, Faculty of Medicine, \\ Tanta University, Tanta, Egypt; \\ ${ }^{4}$ Department of Internal Medicine, Henry \\ Ford Allegiance Health, Jackson, MI \\ 4920I, USA; ${ }^{5}$ Institute for Physical \\ Activity and Nutrition (IPAN), School of \\ Exercise and Nutrition Sciences, Deakin \\ University, Melbourne, Australia
}

*These authors contributed equally to this work
Correspondence: Sherief Ghozy

Faculty of Medicine, Mansoura University,

Mansoura 35516, Egypt

Email sherief_ghozy@yahoo.com
Purpose: We aimed to test if blood transfusion is a risk factor for the prevalence of cancer. Patients and Methods: We conducted secondary analyses using the NHANES database from 1999 to 2016 . We included all individuals who received a blood transfusion with known cancer comorbidity (diseased or not). We used univariate logistic regression to identify any possible association between history of blood transfusion and the prevalence of cancer with adjustment for different co-founders was done. Regression results were expressed as odds ratios (ORs) and 95\% confidence interval $(95 \% \mathrm{CI})$ for both adjusted and unadjusted models. Results: A total of 48,796 individuals were included in the final analysis: 6333 of them received a blood transfusion, while the other 42,463 individuals did not. In individuals who received a blood transfusion, the most prevalent cancer was breast cancer (3.4\%), followed by prostate $(3.0 \%)$, non-melanoma skin $(2.4 \%)$ cancers, while non-melanoma skin $(1.2 \%)$, prostate $(1.1 \%)$ and breast $(1.1 \%)$ cancers were the most prevalent in the no transfusion individuals. There was a significant association between the reported history of blood transfusion and the overall prevalence of cancer in both the unadjusted $(\mathrm{OR}=3.47 ; 95 \%$ $\mathrm{CI}=3.23-0.72 ; \mathrm{P}$-value $<0.001)$ and adjusted model $(\mathrm{OR}=1.86 ; 95 \% \mathrm{CI}=1.72-0.2 .01$; $\mathrm{P}$-value $<0.001)$. On the level of individual cancers, a significant reduction in cancer prevalence was found in patients with breast, cervix, larynx, Hodgkin's lymphoma, melanoma, prostate, skin (non-melanoma), skin (unspecified), soft tissue, testicular, thyroid, and uterine cancers.

Conclusion: Results did not imply any concrete association between cancer risk and history of blood transfusion. These findings would help in debunking the myth of increased cancer risk following blood transfusion.

Keywords: blood transfusion, cancer, association, prevalence

\section{Introduction}

Blood transfusion is considered to be an indispensable choice for many people with acute and chronic conditions which results in the improvement of tissue perfusion and oxygen delivery. It is often used as a lifesaving treatment for the correction of physiologic abnormalities in acute anemia or hemorrhage. It is also used in different surgical procedures as an emergency treatment of surgical induced hemorrhage. However, the decision for blood transfusion should be taken carefully and after weighing both risks and benefits to the patient, as beneficial outcomes are coupled with multiple adverse reactions, including, but not limited to, infections, transfusion-associated immune modulations and incompatible host responses. ${ }^{1}$

Blood transfusion can be either the transfusion of whole blood or blood components. Component transfusion includes red blood cells (RBC), plasma, platelets, 
cryoprecipitates, and fractionated plasma products including intravenous immunoglobulins (IVIGs), albumin, or plasma-derived coagulation factors for replacement. ${ }^{1,2}$ The main indication of RBC transfusion depends on the transfusion trigger, which is the hemoglobin $(\mathrm{Hb})$ level below which the transfusion is needed. It is postulated by the strategy of restrictive transfusion rule of $\mathrm{Hb}$ of $7.0 \mathrm{~g} / \mathrm{dl}$ in critically ill patients, where $\mathrm{Hb}$ concentrations are maintained at 7.0 through $9.0 \mathrm{~g} / \mathrm{dl}$ as per The Transfusion Requirements in Critical Care (TRICC) trial recommendations, with the exception in unstable angina and acute myocardial infarction. ${ }^{3}$ At this level, the benefit of blood transfusion outweighs its risks. The patient's comorbidities also need to be thoroughly evaluated before the decision is made for RBC transfusion. ${ }^{1,2}$ Plasma transfusion is usually indicated for ascitic patients to provide plasma proteins, mainly albumin. ${ }^{4}$ Furthermore, plasma is administered for different coagulopathies, including idiopathic thrombocytopenic purpura. ${ }^{5}$ The main clinical indication for plasma transfusion is the international normalized ratio (INR) above 2, prothrombin time (PT) above 1.5, and prolonged thromboplastin time (PTT) more than 2 times. $^{1,2}$ Platelet transfusion is indicated in defective platelet number or function. Meanwhile, cryoprecipitate is used mainly for dysfibrinogenemia and hypofibrinogenemia. ${ }^{1,2,4}$ IVIG is frequently used to treat immune paraneoplastic diseases and may also prevent tumor cell migration. ${ }^{6}$

Well documented side effects of blood transfusion include acute hemolytic transfusion reaction caused mainly by $\mathrm{ABO}$ mismatch. ${ }^{7}$ Moreover, allergic reactions, ranging from mild urticaria to severe anaphylaxis, are well-documented in the history of medicine. Other causes of high morbidity and mortality following transfusion, are transfusion-related acute lung injury (TRALI), circulatory overload, and transfusion dyspnea. ${ }^{7,8}$ These side effects typically occur within a short time after transfusion.

There is, however, contradicting evidence regarding the long-term effects of blood transfusion in populations with or without co-morbid conditions. ${ }^{8}$ Long-term mortality was evaluated in cardiac patients and was significantly associated with high mortality for up to one year. ${ }^{9}$ Another study found that blood transfusion is a strong predictor of mortality in blunt trauma patients ${ }^{10}$ and increased mortality by three folds. A serious potential long-term side effect is the transmission of chronic infectious viral diseases, including Ebstein-Barr Virus [EBV], Hepatitis C [HCV], or Human Immunodeficiency Virus [HIV]. ${ }^{8}$ In every
2 million units transfer, the risk of $\mathrm{HCV}$ or HIV is 1 . The potential for West Nile virus transmission is more, as it is transferred in every 350,000 units. However, the risk of infections had a regional difference as evidenced in developed countries where there is less risk of infections. ${ }^{8}$

An immensely interesting side effect currently under investigation is the risk of cancer after transfusion. A study reported that after 5-29 years from a blood transfusion, there is a $26 \%$ risk of developing non-Hodgkin's lymphoma [NHL]. ${ }^{11}$ Another study in UK women confirmed these findings and found that there is also an associated increase in liver cancer. ${ }^{12}$ In a study based on the Surveillance, Epidemiology, and End Results (SEER) database, there was a high risk for cancer within 1 year after transfusion. After this interval, there was no significant risk for cancer. Of note, specific types of cancer showed a significant increase, including stomach, liver, kidney, lip, lymphoma, leukemia, respiratory system, and gastrointestinal tract [GIT]. ${ }^{13}$ However, it still depends on the interval between transfusion and cancer risk. GIT, renal cancer, and lymphoma were seen in the first year. In the second year, leukemia, liver, oral and pharyngeal carcinoma were diagnosed. ${ }^{13}$

On the contrary, a different study claimed that there is no risk of cancer after blood transfusion. ${ }^{14}$ Besides, lifestyle habits, including cigarette smoking and alcohol are determining factors for the risk of developing cancer and can be confounding factors in the studies connecting transfusion to cancer diagnosis. ${ }^{15}$ In this study, we aimed to examine any possible association between cancer prevalence and history of blood transfusion.

\section{Patients and Methods}

\section{Data Source and Variable Selection}

A secondary analysis was performed using the NHANES database conducted between the years 1999-2016 using 9 surveys (1999-2000, 2001-2002, 2003-2004, 2005-2006, 2007-2008, 2009-2010, 2011-2012, 2013-2014 and 2015-2016) by the National Center for Health Statistics of the Centers for Disease Control and Prevention (CDC). We retrieved several variables from the database, including age (in years), gender (male or female), marital status (married, widowed, divorced, separated, never married and living with a partner), race (Mexican American, other Hispanic, non-Hispanic white, non-Hispanic African American and other, including multi-racial), educational level (12th grade without a diploma or less, high school 
graduate GED or equivalent, some college course or AA degree, college graduate or higher, and other [do not know or refused]), blood transfusion status (received or not), year of blood transfusion (before 1972, 1972-1991 and 1992 to present), cancer status (diseased or not) and cancer type (bladder, blood, bone, brain, breast, cervix [cervical], colon, esophagus [esophageal], gallbladder, kidney, larynx/windpipe, leukemia, liver, lung, lymphoma/ Hodgkin's disease, melanoma, mouth/tongue/lip, nervous system, ovary [ovarian], pancreas [pancreatic], prostate, rectum [rectal], skin [non-melanoma], skin [do not know what kind], soft tissue [muscle or fat], stomach, testis [testicular], thyroid, uterus [uterine] and other).

\section{Inclusion and Exclusion Criteria}

We included all individuals who received a blood transfusion with known cancer comorbidity (diseased or not). We excluded all individuals who had missing, declined, or did not know whether they had previously received a blood transfusion, in addition to individuals who had missing data or did not know their cancer comorbidity (diseased or not).

\section{Statistical Analysis}

All data were analyzed using $\mathrm{R}$ software version 3.6.2 ${ }^{16}$ using the packages $(\mathrm{Rcmdr})^{17}$ and $(\mathrm{glm} 2) .{ }^{18}$ All variables were represented as frequencies, and percentages with Chi2 test (or Fisher's exact test, as appropriate) was used for testing the difference, according to the blood transfusion status. We used univariate logistic regression to identify any possible association between history of blood transfusion and the prevalence of cancer. Moreover, adjustment for different co-founders was done; including age, gender, race, marital status, and education of the included patients. ${ }^{19}$ Regression results were expressed as odds ratios (ORs) and 95\% confidence interval (95\% CI) for both adjusted and unadjusted models.

\section{Results}

\section{Characteristics of the Included Individuals}

A total of 48,796 individuals were included in the final analysis; 6333 of them received a blood transfusion, while the other 42,463 individuals did not. About half of the individuals (43.8\%), with transfusion history, had received blood following 1992. Moreover, cancer history was reported in $21.4 \%$ of the transfusion group, compared to only $7.3 \%$ for no transfusion group. In individuals who received a blood transfusion, the most prevalent cancer was breast cancer $(3.4 \%)$, followed by prostate $(3.0 \%)$, non-melanoma skin $(2.4 \%)$ cancers, while non-melanoma skin $(1.2 \%)$, prostate $(1.1 \%)$ and breast $(1.1 \%)$ cancers were the most prevalent in the no transfusion individuals.

In the blood transfusion group, the most common age group was 70-100 years (41.3\%) followed by 60-69 years (22.2\%), 50-59 years (15.1\%), and 40-49 years $(10.7 \%)$, respectively. Moreover, there was a significant difference in age groups when comparing the included individuals according to their blood transfusion history. A similar difference was found in gender distribution, with a male percentage of $39.9 \%$ and $49.2 \%$ in individuals with a history of blood transfusion and no history, respectively. As presented in Table 1, all other characteristics show significant differences among included individuals when compared on basis of blood transfusion history; including marital status, race, education, year of blood transfusion, overall cancer prevalence, and specific cancer type prevalence.

\section{Association with the Risk of Cancer}

There was a significant association between the reported history of blood transfusion and overall prevalence of cancer; this was evident in both unadjusted (OR [95\% $\mathrm{CI}]=3.47$ [3.23-3.72]; P-value $<0.001)$ and adjusted models (OR [95\% CI] $=1.86$ [1.72-2.01]; P-value < 0.001). This association appears to be more related to blood transfusions done following the year 1992 (OR $[95 \% \mathrm{CI}]=1.25[1.07-1.45]$; P-value $=0.005)$. On adjusting for different co-founding factors, an increase in the association level was detected in transfusion done following 1992 (OR [95\% CI] = 1.63 [1.38-1.92]; P-value < $0.001)$, as well as the association for transfusion years 1972-1991 turned into a significant level (OR [95\% CI] $=1.33$ [1.11-1.60]; P-value = 0.002) (Table 2).

On the level of individual cancers, there was an increase in the prevalence rate among adjusted (OR $[95 \% \mathrm{CI}]=1.82[0.75-4.44])$ and unadjusted $(\mathrm{OR}[95 \%$ $\mathrm{CI}]=1.34$ [0.56-3.2]) models of bone cancer and adjusted model of liver cancer (OR [95\% CI] $=1.04$ [0.37-2.93]). Noteworthy, a significant reduction in cancer prevalence was found in patients with breast, cervix, larynx, Hodgkin's lymphoma, melanoma, prostate, skin (nonmelanoma), skin (unspecified), soft tissue, testicular, thyroid, and uterine cancers (Supplementary Table 1). Figure 1 shows the graphical presentation of both adjusted and unadjusted models for all cancer types. 
Table I Characteristics of the Included Individuals

\begin{tabular}{|c|c|c|c|}
\hline \multirow[t]{2}{*}{ Variables; n (\%) } & \multicolumn{2}{|c|}{$\begin{array}{l}\text { Received Blood } \\
\text { Transfusion }\end{array}$} & \multirow[t]{2}{*}{$P$ value } \\
\hline & Yes (6333) & No $(42,463)$ & \\
\hline \multicolumn{4}{|l|}{ Age (years) } \\
\hline $20: 29$ & 258 (4.I) & 8431 (19.9) & \multirow{6}{*}{$<0.00 I^{*}$} \\
\hline $30: 39$ & $421(6.6)$ & 7920 (18.7) & \\
\hline $40: 49$ & $679(10.7)$ & $7493(17.6)$ & \\
\hline $50: 59$ & $954(15.1)$ & $6116(14.4)$ & \\
\hline $60: 69$ & I 407 (22.2) & $6225(14.7)$ & \\
\hline $70: 100$ & $2614(4 \mid .3)$ & $6278(14.8)$ & \\
\hline \multicolumn{4}{|l|}{ Gender } \\
\hline Male & 2525 (39.9) & $20,873(49.2)$ & \multirow[t]{2}{*}{$<0.001 *$} \\
\hline Female & $3808(60.1)$ & $21,590(50.8)$ & \\
\hline \multicolumn{4}{|l|}{ Marital status } \\
\hline Married & $3179(50.2)$ & $22,212(52.3)$ & \multirow{6}{*}{$<0.001 *$} \\
\hline Widowed & I $267(20.0)$ & $317 \mid(7.5)$ & \\
\hline Divorced & 807 ( 12.7$)$ & $4052(9.5)$ & \\
\hline Separated & $199(3.1)$ & $1388(3.3)$ & \\
\hline Never married & $559(8.8)$ & 7921 (18.7) & \\
\hline Living with partner & $24 \mid(3.8)$ & $3222(7.6)$ & \\
\hline \multicolumn{4}{|l|}{ Race } \\
\hline Mexican American & $849(13.4)$ & 7920 (I8.7) & \multirow{5}{*}{$<0.001 *$} \\
\hline Other Hispanic & $436(6.9)$ & $3526(8.3)$ & \\
\hline Non-Hispanic White & $3395(53.6)$ & $18,543(43.7)$ & \\
\hline Non-Hispanic Black & I $338(2 \mid .1)$ & $8773(20.7)$ & \\
\hline $\begin{array}{l}\text { Other Race - } \\
\text { Including Multi-Racial }\end{array}$ & $315(5.0)$ & 3701 (8.7) & \\
\hline \multicolumn{4}{|l|}{ Education } \\
\hline $\begin{array}{l}\text { 12th grade without } \\
\text { diploma or less }\end{array}$ & $2042(32.2)$ & II,805 (27.8) & \multirow{6}{*}{$<0.00 I^{*}$} \\
\hline High school graduate & 1470 (23.2) & $9776(23.0)$ & \\
\hline GED or equivalent & & & \\
\hline $\begin{array}{l}\text { Some college courses } \\
\text { or AA degree }\end{array}$ & 1724 (27.2) & II,659 (27.5) & \\
\hline $\begin{array}{l}\text { College graduate or } \\
\text { higher }\end{array}$ & $1084(17.1)$ & $9147(21.5)$ & \\
\hline Other & $12(0.2)$ & $72(0.2)$ & \\
\hline \multicolumn{4}{|l|}{$\begin{array}{l}\text { Year received blood } \\
\text { transfusion }\end{array}$} \\
\hline Before 1972 & $1476(23.3)$ & NA & $<0.00 I^{*}$ \\
\hline |972-199| & $1872(29.6)$ & & \\
\hline 1992 to present & $2777(43.8)$ & & \\
\hline \multicolumn{4}{|l|}{ Cancer } \\
\hline Yes & | 357 (21.4) & $3096(7.3)$ & $<0.001 *$ \\
\hline No & $4976(78.6)$ & 39,367 (92.7) & \\
\hline
\end{tabular}

(Continued)
Table I (Continued).

\begin{tabular}{|c|c|c|c|}
\hline \multirow[t]{2}{*}{ Variables; n (\%) } & \multicolumn{2}{|c|}{$\begin{array}{l}\text { Received Blood } \\
\text { Transfusion }\end{array}$} & \multirow[t]{2}{*}{$P$ value } \\
\hline & Yes (6333) & No $(42,463)$ & \\
\hline \multicolumn{4}{|l|}{ Type of cancer } \\
\hline Bladder & $48(0.8)$ & $61(0.1)$ & \\
\hline Blood & $3(0.0006)$ & $5(0.000 I)$ & \\
\hline Bone & $17(0.3)$ & $12(0.0003)$ & $<0.00 I^{*}$ \\
\hline Brain & $6(0.1)$ & $10(0.0003)$ & \\
\hline Breast & $214(3.4)$ & $476(1.1)$ & \\
\hline Cervix (cervical) & $60(0.9)$ & $235(0.6)$ & \\
\hline Colon & $138(2.2)$ & $152(0.4)$ & \\
\hline $\begin{array}{l}\text { Esophagus } \\
\text { (esophageal) }\end{array}$ & $7(0.1)$ & $13(0.0003)$ & \\
\hline Gallbladder & $0(0.0)$ & I (0.0) & \\
\hline Kidney & $38(0.6)$ & $36(0.1)$ & \\
\hline Larynx/windpipe & $5(0.1)$ & $19(0.0004)$ & \\
\hline Leukemia & $16(0.3)$ & $27(0.1)$ & \\
\hline Liver & $10(0.2)$ & $10(0.0003)$ & \\
\hline Lung & $46(0.7)$ & $67(0.2)$ & \\
\hline $\begin{array}{l}\text { Lymphoma/Hodgkin's } \\
\text { disease }\end{array}$ & $30(0.5)$ & $61(0.1)$ & \\
\hline Melanoma & $57(0.9)$ & $191(0.4)$ & \\
\hline Mouth/tongue/lip & $7(0.1)$ & $18(0.0005)$ & \\
\hline Nervous system & $0(0.0)$ & I $(0.0)$ & \\
\hline Ovary (ovarian) & $37(0.6)$ & $62(0.1)$ & \\
\hline Pancreas (pancreatic) & $3(0.0)$ & $8(0.0002)$ & \\
\hline Prostate & $188(3.0)$ & $486(1.1)$ & \\
\hline Rectum (rectal) & $8(0.1)$ & II (0.0003) & \\
\hline Skin (non-melanoma) & I54 (2.4) & $508(1.2)$ & \\
\hline $\begin{array}{l}\text { Skin (do not know what } \\
\text { kind) }\end{array}$ & $107(1.7)$ & $243(0.6)$ & \\
\hline $\begin{array}{l}\text { Soft tissue (muscle or } \\
\text { fat) }\end{array}$ & $2(0.0004)$ & $8(0.0002)$ & \\
\hline Stomach & $16(0.3)$ & $20(0.0004)$ & \\
\hline Testis (testicular) & $6(0.1)$ & $22(0.1)$ & \\
\hline Thyroid & $16(0.3)$ & $63(0.1)$ & \\
\hline Uterus (uterine) & $56(0.9)$ & $130(0.3)$ & \\
\hline Others & $57(0.9)$ & $|2|(0.3)$ & \\
\hline
\end{tabular}

Note: *Statistically significant.

Abbreviation: NA, not applicable.

\section{Discussion}

In this study, we investigated the association between the prevalence of cancer and the history of blood transfusion using a large cohort database. Our results did not imply any concrete association between cancer risk and history of blood transfusion. Blood transfusions are associated 
Table 2 Logistic Regression of the Association Between Blood Transfusion and Cancer Prevalence

\begin{tabular}{|c|c|c|c|c|c|c|c|}
\hline \multirow[t]{2}{*}{ Predictor } & \multirow[t]{2}{*}{ Estimateף } & \multirow[t]{2}{*}{ SE } & \multirow[t]{2}{*}{$\mathbf{Z}$} & \multirow[t]{2}{*}{ P-value } & \multirow[t]{2}{*}{ Odds Ratio } & \multicolumn{2}{|c|}{ 95\% Confidence Interval } \\
\hline & & & & & & Lower & Upper \\
\hline \multicolumn{8}{|c|}{ Blood transfusion (unadjusted) } \\
\hline No & Reference & & & & & & \\
\hline Yes & 1.24 & 0.04 & 34.67 & $<0.00 I^{*}$ & 3.47 & 3.23 & 3.72 \\
\hline \multicolumn{8}{|c|}{ Blood transfusion (adjusted ${ }^{*}$ ) } \\
\hline No & Reference & & & & & & \\
\hline Yes & 0.62 & 0.04 & 15.91 & $<0.001 *$ & 1.86 & 1.72 & 2.01 \\
\hline \multicolumn{8}{|c|}{ Year of blood transfusion (unadjusted) } \\
\hline Before 1972 & Reference & & & & & & \\
\hline$|972-199|$ & -0.09 & 0.09 & -0.98 & 0.328 & 0.92 & 0.77 & 1.09 \\
\hline 1992 to present & 0.22 & 0.08 & 2.78 & $0.005^{*}$ & 1.25 & 1.07 & 1.45 \\
\hline \multicolumn{8}{|c|}{ Year of blood transfusion (adjusted ${ }^{*}$ ) } \\
\hline Before 1972 & Reference & & & & & & \\
\hline |972-199| & 0.29 & 0.09 & 3.03 & $0.002^{*}$ & 1.33 & 1.11 & 1.60 \\
\hline 1992 to present & 0.49 & 0.08 & 5.73 & $<0.001 *$ & 1.63 & 1.38 & 1.92 \\
\hline
\end{tabular}

Notes: ๆEstimates represent the log odds of "Cancer = Yes" vs. "Cancer = No"; ¥Adjusted for age, gender, race, marital status, and education of the included patients; *Statistically significant.

with both risks and benefits. In transfusion medicine, the current hypothesis on the mechanism of carcinogenesis points toward the synergism of immunosuppression and the existence of viruses as the main risk factors. ${ }^{18}$ There may be an involvement of unknown genetic mechanisms, that may make susceptible genotypes behave differently after a blood transfusion. ${ }^{18}$

Our analysis revealed an overall increased rate of cancer among patients with a history of blood transfusion, and these rates were higher following 1972. However, there was no significant increased rate of individual cancer types in patients who received a blood transfusion. In addition, in the unadjusted analysis, there was a significantly decreased prevalence of breast, cervix, larynx, lymphoma, melanoma, prostate, skin, testis, thyroid, and uterus. Furthermore, after adjustment for age, gender, race, marital status, and education of the included patients, there was still a decreased prevalence of breast, cervix, prostate, melanoma, and thyroid cancers.

There is still a controversy over the risk of cancer in patients receiving blood transfusion. ${ }^{7,8}$ In our study, we did not find any significant risk of cancer in those patients. Our results partially coincide with the results of another study that found that there was no increased risk of cancer after four years of transfusion. ${ }^{13}$ In the same study, they found that there was an increased risk of liver cancer within 13-30 years, but this increased risk was eliminated after adjusting for the patients' characteristics. ${ }^{13}$

Notwithstanding, our study results contradict the results of similar studies. In a large cohort of UK women, blood transfusion was associated with increased risk of liver and non-Hodgkin lymphoma. ${ }^{12}$ They found that the risk increased within five years for most cancers suggesting subclinical cancer foci. However, after five years, an increase was noted only in liver cancer and nonHodgkin lymphoma. ${ }^{12}$ The same results were obtained in the Danish study, which found that there was an increased risk of liver and non-Hodgkin lymphoma. ${ }^{15}$ Another study, based on the SEER registry, implied that there was an increased overall risk of cancer within the first year after blood transfusion. There was also a site-specific increased risk of stomach, colon, liver, kidney, renal pelvis and ureter, myeloma, leukemia, and leukemia. ${ }^{13}$

All studies that investigated the risk of cancer after blood transfusion found that there is a temporal dependent risk association. ${ }^{11-15,20}$ The risk decreases over time and after a specific period, there was no risk of cancer. This was explained as a reverse causation relationship and that the increased risk of cancer after transfusion does not necessarily mean that the transfusion is the cause of 


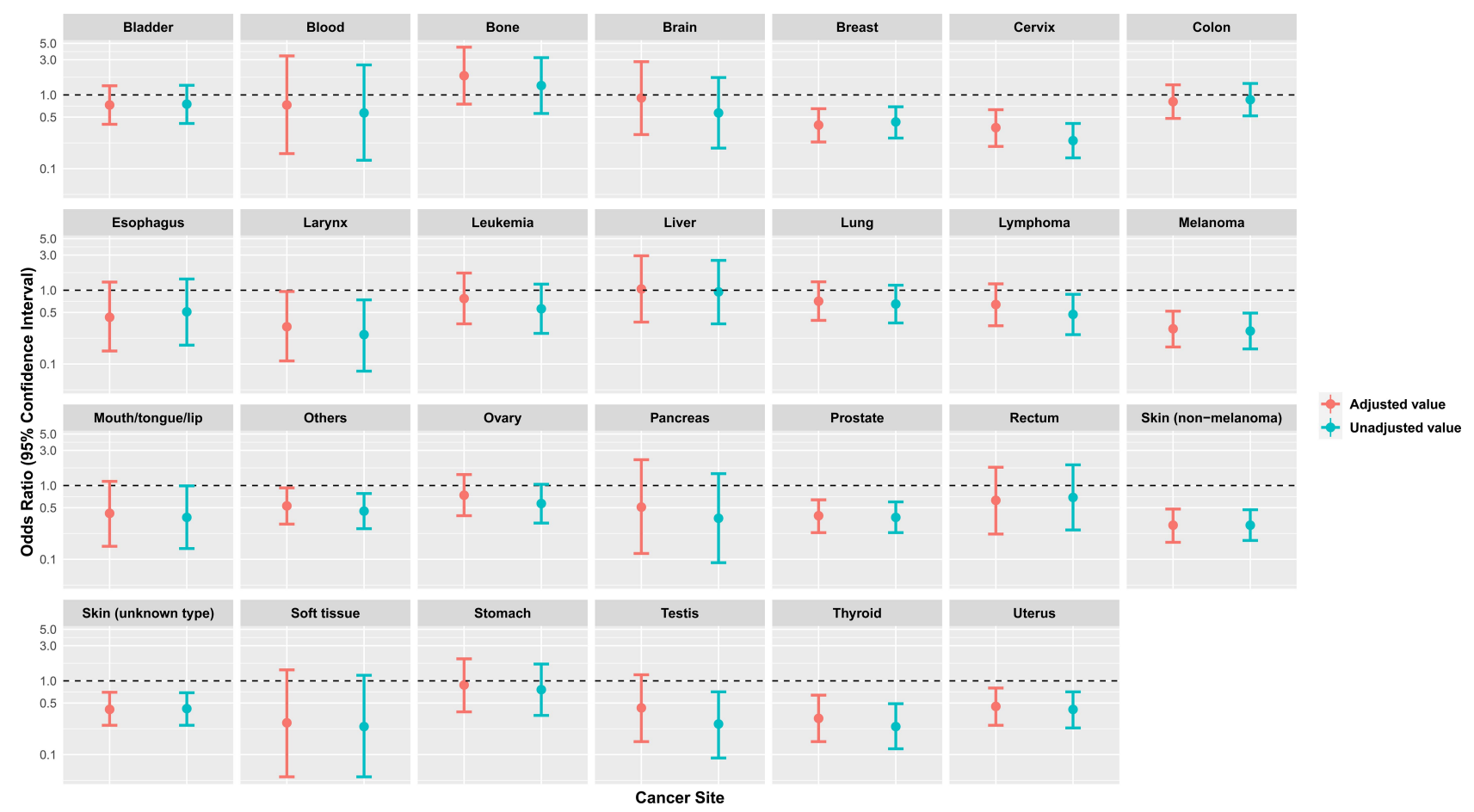

Figure I Showing the unadjusted and adjusted odds ratio (OR) and the corresponding $95 \%$ confidence interval $(\mathrm{Cl})$ of the association between blood transfusion and cancer site.

cancer. $^{13}$ Precancerous lesions or cancer itself may lead to anemia that is treated through blood transfusion, which explains the increased risk for specific cancers. ${ }^{13,21}$ Other causes should be considered including lifestyle habits of alcohol, smoking, and the presence of occult cancer foci. ${ }^{8,12,22}$ In another study, the increased cancer risk was mainly attributed to the transfer of carcinogenic infectious agents like EBV, HIV, and HCV. This explains why there was an increased risk for specific cancers, such as lymphoma and liver cancer. $^{22}$

At this juncture, it is very important to discuss the speculated immunomodulatory effect of blood transfusion, referred to as transfusion-induced immune modulation (TRIM). A study of the change in specific immunological functions in human subjects and mice following blood transfusion, has shown decreases in interleukin 2 (IL-2) secretion, natural killer (NK) cell activity and thus, reduced macrophage activity, abnormal CD4/CD8 ratios and immune surveillance against malignancy, and could be either antigen-specific/nonspecific in response. This ends up indirectly enabling malignant proliferation and cell growth, tethering, and dissemination. ${ }^{6}$ The role of viruses themselves has also been implicated as a cause of immunosuppression after blood transfusion. ${ }^{23}$ Ergo, immune suppression, and viruses are most likely intertwined as cofactors in the controversial theory of carcinogenesis. ${ }^{23,24}$

The current study has some limitations; we performed a secondary analysis using cross-sectional data where the temporal relationship could not be investigated, to validate the findings. Secondly, the data for blood transfusion frequency or quantity may have been skewed by the recall bias of patients. Lastly, we were not able to exclude the criteria of other possible risk factors of cancer e.g. smoking, alcohol, and chronic immunosuppressive medications, which may influence the results as confounding clinical and pathological factors.

\section{Conclusion}

Our study results did not imply any concrete association between cancer risk and history of blood transfusion. Our results may have important implications in cancer biology, clinical medicine, and public health of debunking the myth of increased cancer risk following blood transfusion. Efforts to surgically minimize blood loss, implement alternative strategies for blood replacement and restrictive transfusion criteria must also continue meanwhile. 


\section{Ethics Approval and Informed Consent}

The survey protocol was approved by the Institutional Review Board of the Centers for Disease Control and Prevention (Protocol \#98-12, Protocol \#2005-06, Continuation of Protocol \#2005-06, Protocol \#2011-17). Written informed consent was obtained from all subjects.

\section{Disclosure}

The authors report no conflicts of interest in this work.

\section{References}

1. Yaddanapudi S, Yaddanapudi L. Indications for blood and blood product transfusion. Indian $J$ Anaesth. 2014;58(5):538-542. doi:10.4103/0019-5049.144648

2. Nuttall GA, Brost BC, Connis RT, et al. Practice guidelines for perioperative blood transfusion and adjuvant therapies: an updated report by the American Society of anesthesiologists task force on perioperative blood transfusion and adjuvant therapies. Anesthesiology. 2006;105(1):198-208. doi:10.1097/00000542-20060 7000-00030

3. Hébert PC, Wells G, Blajchman MA, et al. A multicenter, randomized, controlled clinical trial of transfusion requirements in critical care. $N$ Engl $J$ Med. 1999;340(6):409-417. doi:10.1056/ NEJM199902113400601

4. O'Shaughnessy DF, Atterbury C, Bolton Maggs P, et al. Guidelines for the use of fresh-frozen plasma, cryoprecipitate and cryosupernatant. $\mathrm{Br}$ J Haematol. 2004;126(1):11-28. doi:10.1111/j.1365-2141.2004.04972. $\mathrm{x}$

5. Sharma S, Sharma P, Tyler LN. Transfusion of blood and blood products: indications and complications. Am Fam Physician. 2011;83 (6):719-724.

6. Goubran HA, Elemary M, Radosevich M, Seghatchian J, El-Ekiaby M, Burnouf T. Impact of transfusion on cancer growth and outcome. Cancer Growth Metastasis. 2016;9:CGM.S32797. doi:10.4137/CGM. S32797

7. Sahu S, Hemlata H, Verma A. Adverse events related to blood transfusion. Indian J Anaesth. 2014;58(5):543-551. doi:10.4103/ 0019-5049.144650

8. Rawn J. The silent risks of blood transfusion. Curr Opin Anaesthesiol. 2008;21(5):664-668. doi:10.1097/ACO.0b013e32830f1fd1

9. Shishehbor MH, Madhwal S, Rajagopal V, et al. Impact of blood transfusion on short- and long-term mortality in patients with ST-segment elevation myocardial infarction. JACC Cardiovasc Interv. 2009;2(1):46-53. doi:10.1016/j.jcin.2008.09.011
10. Charles A, Shaikh AA, Walters M, Huehl S, Pomerantz R. Blood transfusion is an independent predictor of mortality after blunt trauma. Am Surg. 2007;73(1):1-5. doi:10.1177/000313480707300101

11. Cerhan JR, Engels EA, Cozen W, et al. Blood transfusion, anesthesia, surgery and risk of non-hodgkin lymphoma in a population-based case-control study. Int J Cancer. 2008;123(4):888-894. doi:10.1002/ ijc. 23561

12. Yang TO, Cairns BJ, Reeves GK, Green J, Beral V, collaborators MWS. Cancer risk among 21st century blood transfusion recipients. Ann Oncol. 2017;28(2):393-399. doi:10.1093/annonc/mdw555

13. Riedl R, Engels EA, Warren JL, Berghold A, Ricker W, Pfeiffer RM. Blood transfusions and the subsequent risk of cancers in the United States elderly. Transfusion. 2013;53(10):2198-2206. doi:10.1111/ trf.12071

14. Edgren G, Hjalgrim H, Reilly M, et al. Risk of cancer after blood transfusion from donors with subclinical cancer: a retrospective cohort study. Lancet. 2007;369(9574):1724-1730. doi:10.1016/ S0140-6736(07)60779-X

15. Hjalgrim H, Edgren G, Rostgaard K, et al. Cancer incidence in blood transfusion recipients. J Natl Cancer Inst. 2007;99(24):1864-1874. doi:10.1093/jnci/djm248

16. R Core Team (2014). R: A language and environment for statistical computing. R Foundation for Statistical Computing, Vienna, Austria. Available from: https://www.r-project.org/. Accessed September 30, 2020.

17. Rcmdr: R commander. Version 2.6-2. 2020. Available from: https:// CRAN.R-project.org/package=Rcmdr. Accessed March 22, 2020.

18. glm2: fitting generalized linear models. Version 1.2.1. 2018. Available from: https://CRAN.R-project.org/package $=\mathrm{glm} 2$. Accessed March 22, 2020.

19. Jiang H, Kulkarni PM, Mallinckrodt CH, Shurzinske L, Molenberghs G, Lipkovich I. Covariate adjustment for logistic regression analysis of binary clinical trial data. Stat Biopharm Res. 2017;9(1):126-134. doi:10.1080/19466315.2016.1234973

20. Cerhan JR, Wallace RB, Folsom AR, Potter JD, Munger RG, Prineas RJ. Transfusion history and cancer risk in older women. Ann Intern Med. 1993;119(1):8-15. doi:10.7326/0003-4819-1191-199307010-00002

21. Edgren G, Bagnardi V, Bellocco R, et al. Pattern of declining hemoglobin concentration before cancer diagnosis. Int J Cancer. 2010;127 (6):1429-1436. doi:10.1002/ijc.25122

22. Martin D, Gutkind JS. Human tumor-associated viruses and new insights into the molecular mechanisms of cancer. Oncogene. 2008;27(Suppl 2):S31-S42. doi:10.1038/onc.2009.351

23. Kirkley SA. Proposed mechanisms of transfusion-induced immunomodulation. Clin Diagn Lab Immunol. 1999;6(5):652-657. doi:10.1128/CDLI.6.5.652-657.1999

24. Moore PS, Chang Y, Condit RC. Common commensal cancer viruses. PLoS Pathog. 2017;13(1):e1006078. doi:10.1371/journal. ppat. 1006078
Clinical Epidemiology

\section{Publish your work in this journal}

Clinical Epidemiology is an international, peer-reviewed, open access, online journal focusing on disease and drug epidemiology, identification of risk factors and screening procedures to develop optimal preventative initiatives and programs. Specific topics include: diagnosis, prognosis, treatment, screening, prevention, risk factor modification,

Submit your manuscript here: https://www.dovepress.com/clinical-epidemiology-journal
Dovepress

systematic reviews, risk \& safety of medical interventions, epidemiology \& biostatistical methods, and evaluation of guidelines, translational medicine, health policies \& economic evaluations. The manuscript management system is completely online and includes a very quick and fair peer-review system, which is all easy to use. 